Article

\title{
Nanocrystalline $\mathrm{BaSnO}_{3}$ as an Alternative Gas Sensor Material: Surface Reactivity and High Sensitivity to $\mathrm{SO}_{2}$
}

\author{
Artem Marikutsa ${ }^{1, *}$, Marina Rumyantseva ${ }^{1, \dagger}$, Alexander Baranchikov ${ }^{2, \dagger}$ \\ and Alexander Gaskov ${ }^{1, \dagger}$ \\ ${ }^{1}$ Chemistry Department, Moscow State University, Leninskie Gory 1-3, Moscow 119991, Russia; \\ E-Mails: roum@inorg.chem.msu.ru (M.R.); gaskov@inorg.chem.msu.ru (A.G.) \\ ${ }^{2}$ Kurnakov Institute of General and Inorganic Chemistry, Leninskiy prospect 31, Moscow 119991, \\ Russia; E-Mail: a.baranchikov@yandex.ru \\ $\dagger$ These authors contributed equally to this work. \\ * Author to whom correspondence should be addressed; E-Mail: artem.marikutsa@ gmail.com; \\ Tel.: +7-495-939-5471; Fax: +7-495-939-0998.
}

Academic Editor: Elisabetta Comini

Received: 14 July 2015 / Accepted: 11 September 2015 / Published: 18 September 2015

\begin{abstract}
Nanocrystalline perovskite-type $\mathrm{BaSnO}_{3}$ was obtained via microwave-assisted hydrothermal route followed by annealing at variable temperature. The samples composition and microstructure were characterized. Particle size of 18-23 nm was unaffected by heat treatment at $275-700{ }^{\circ} \mathrm{C}$. Materials DC-conduction was measured at variable temperature and oxygen concentration. Barium stannate exhibited $n$-type semiconductor behavior at $150-450{ }^{\circ} \mathrm{C}$ with activation energy being dependent on the materials annealing temperature. Predominant ionosorbed oxygen species types were estimated. They were shown to change from molecular to atomic species on increasing temperature. Comparative test of sensor response to various inorganic target gases was performed using nanocrystalline $\mathrm{SnO}_{2}$-based sensors as reference ones. Despite one order of magnitude smaller surface area, $\mathrm{BaSnO}_{3}$ displayed higher sensitivity to $\mathrm{SO}_{2}$ in comparison with $\mathrm{SnO}_{2}$. DRIFT spectroscopy revealed distinct interaction routes of the oxides surfaces with $\mathrm{SO}_{2}$. Barium-promoted sulfate formation favoring target molecules oxidation was found responsible for the increased $\mathrm{BaSnO}_{3}$ sensitivity to ppm-range concentrations of $\mathrm{SO}_{2}$ in air.
\end{abstract}


Keywords: barium stannate; sulfur dioxide; nanocrystalline tin dioxide; semiconductor gas sensor; gas-solid interaction

\section{Introduction}

Semiconductor metal oxide $\left(\mathrm{SMO}_{\mathrm{x}}\right)$ based gas sensors suffer from the lack of selectivity to target gases. Its fundamental reason might be that typically utilized $n$-type wide band gap binary oxides, such as $\mathrm{ZnO}, \mathrm{WO}_{3}, \mathrm{In}_{2} \mathrm{O}_{3}$ and most often $\mathrm{SnO}_{2}$ [1], possess a confined variety of active sites on the surface. These include lattice cations and anions, oxygen vacancies, adsorbed oxygen and hydroxyl species [2]. Material science approaches to increase selectivity are aimed at creating specific active sites on the sensor surface. One of them is chemical modification of binary $\mathrm{SMO}_{\mathrm{x}}$ by catalytic (noble metal clusters) or acid/base (transition metal oxides) additives [3]. An alternate way is to utilize oxides with more complex composition instead of binary ones as a semiconductor matrix [1]. According to the materials design concept of Hosono et al. [4], for a complex oxide to behave as an $n$-type semiconductor, it should be comprised of at least one heavy post-transition cation with the electron configuration $(n-1) d^{10} n s^{0}(n \geqslant 4)$. In a metal oxide the valence band maximum is mainly composed of $2 p^{8}$-orbitals of oxygen anions, while conduction band minimum-by $n s^{0}$-orbitals of metal cations [5]. If the oxide structure includes a network of heavy post-transition cations, e.g., $\mathrm{Zn}^{2+}, \mathrm{Cd}^{2+}, \mathrm{In}^{3+}, \mathrm{Sn}^{4+}$, their spatially extended s-orbitals overlap and form widely dispersed conduction band favoring high electron mobility [6]. Barium stannate is an example of such materials that attracted an interest in gas sensor research [7-10]. The perovskite-type cubic structure of $\mathrm{BaSnO}_{3}$ is challenging for sensor material design by cation substitution in $\mathrm{Ba}$ or $\mathrm{Sn}$ positions. Semiconductor characteristics determined by the frame of $\left\{\mathrm{SnO}_{6}\right\}$ octahedra were reported to be varied through either $n$-doping: partial substitution of $\mathrm{Ba}$ by $\mathrm{La}[11,12]$ or substitution of $\mathrm{Sn}$ by $\mathrm{Sb}$ [13-15], or $p$-doping via $\mathrm{Sn}$ substitution by $\mathrm{Ni}, \mathrm{Cr}$, etc. $[12,16,17]$. On the other hand, cation substitution in a complex oxide could open wide perspectives for the optimization of surface reactivity by modifying its adsorptive, acid/base and RedOx properties.

Barium stannate is a semiconductor with experimental values of indirect band gap $E_{g}=3.1-3.4 \mathrm{eV}[14,15,18]$ and direct optical band gap $E_{g}=3.4-3.5 \mathrm{eV}$ [19]. Density functional theory (DFT) calculations describe band structure of $\mathrm{BaSnO}_{3}$ with the conduction band minimum composed of antibonding Sn $5 s-\mathrm{O} 2 s$ orbitals slightly contributed by Ba $6 s$ orbitals. Valence band is mainly consisted of nonbonding O $2 p$ orbitals [20,21]. The band gap was found to increase due to partial substitution of $\mathrm{Sn}$ by $\mathrm{Sb}$ [14]; increasing the calcination temperature of the materials resulted in narrowing the band gap [22]. The synthesis of $\mathrm{BaSnO}_{3}$ is complicated by the need of hard reaction conditions for the formation of perovskite structure. Conventionally obtained by solid-state calcination at $\mathrm{T}>1200{ }^{\circ} \mathrm{C}$ highly crystalline barium stannate was extensively investigated for good dielectric properties with potential use in capacitors [23,24]. With the development of wet-chemistry synthetic routes under mild conditions, e.g., hydrothermal [25-28] and lyothermal [29], ion exchange [30], coprecipitation [31] or polymerized complex methods [11,32], $\mathrm{BaSnO}_{3}$ was found advantageous for other applications. The latter include infrared luminescence [18], photovoltaics [27], thermoelectric materials [11], humidity detection [17,33] and resistive gas sensors. Promising sensor behavior was 
reported in the detection of $\mathrm{CO}$ and $\mathrm{NO}[7,8]$, yet it required high operating temperature of $450-650{ }^{\circ} \mathrm{C}$. Preferred sensitivity to ethanol [31], hydrocarbons [34] and liquefied petroleum gas (LPG) [9] was observed on the background of $\mathrm{H}_{2}, \mathrm{CO}, \mathrm{CH}_{4}$ and benzene.

In this work, the effect of annealing temperature on phase composition, microstructure parameters and electric conduction was evaluated for hydrothermally synthesized nanocrystalline $\mathrm{BaSnO}_{3}$. Sensing behavior to a number of target gases was tested in comparison with nanocrystalline $\mathrm{SnO}_{2}$-based sensors. An increased $\mathrm{SO}_{2}$ sensitivity of $\mathrm{BaSnO}_{3}$ that exceeded that of tin dioxide was observed for the first time and its origin was studied by in situ diffuse reflectance infrared spectroscopy.

\section{Results and Discussion}

\subsection{Materials Composition and Microstructure Parameters}

The powder yielded from hydrothermal treatment of barium-tin hydroxide consisted of $\mathrm{BaSn}(\mathrm{OH})_{6}$ phase with crystallite size $d_{X R D}=21-27 \mathrm{~nm}$ (Figure 1a). The results of as-obtained $\mathrm{BaSn}(\mathrm{OH})_{6}$ analysis by thermogravimetry-differential scanning calorimetry with mass-spectrometric detection of outlet gas (TG-DSC-MS) revealed four features (Figure 1b). The largest mass-loss step accompanied by strong endothermic peak at $275{ }^{\circ} \mathrm{C}$ is due to water elimination (mass number 18 in Figure $1 \mathrm{~b}$ ) that is consistent with the literature [25]. The amount of desorbed water during the first mass-loss stage, which was completed at $\sim 500{ }^{\circ} \mathrm{C}$, equals to the composition $\mathrm{BaSnO}_{3} \cdot 3 \mathrm{H}_{2} \mathrm{O}$ corresponding to $\operatorname{BaSn}(\mathrm{OH})_{6}$. At $\sim 700{ }^{\circ} \mathrm{C}$, a small mass-loss $(0.5 \mathrm{wt} \%)$ along with $\mathrm{CO}_{2}$ evolution peak (mass number 44 ) were observed (Figure $1 \mathrm{~b}$ ). The emergence of an exothermic DSC peak suggests that barium stannate crystallinity increased at this temperature, probably at the expense of some carbonate decomposition. At $1000{ }^{\circ} \mathrm{C}$, additional $\mathrm{CO}_{2}$ evolvement with a slight mass-loss were detected by TG-DSC-MS. Thus, annealing $\mathrm{BaSn}(\mathrm{OH})_{6}$ at the four featured temperatures was performed to obtain distinct barium stannate samples. Tin dioxide samples synthesized for comparison were processed at the same temperatures.

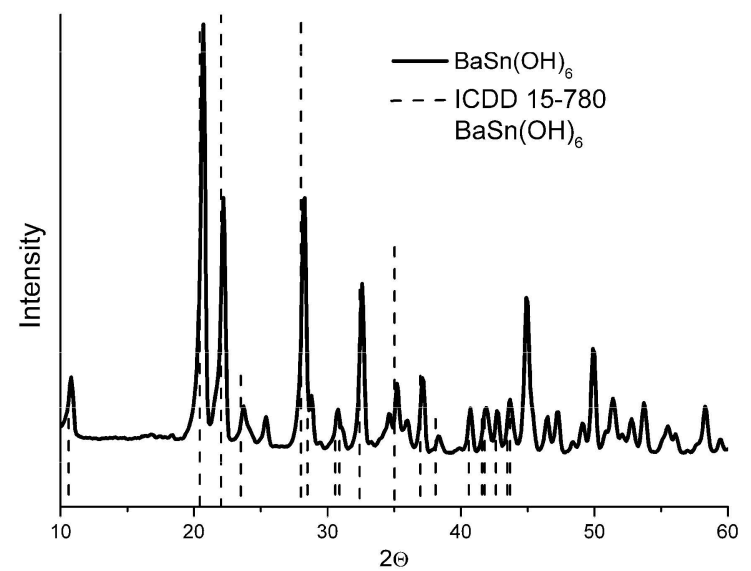

(a)

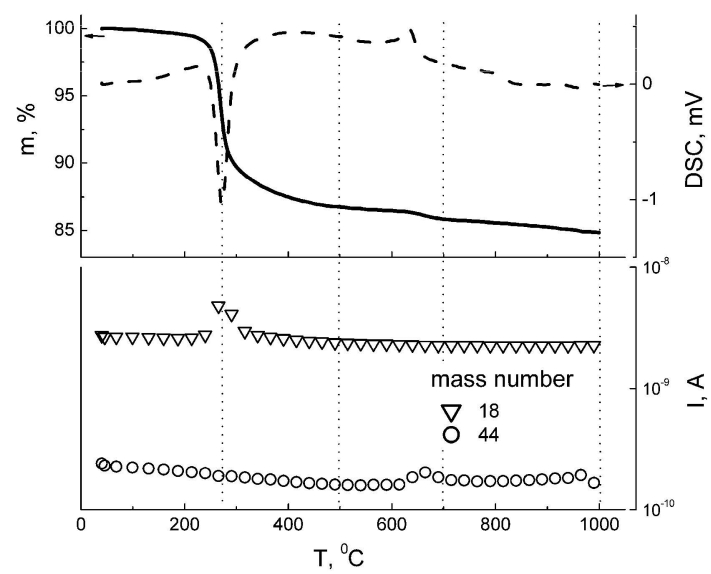

(b)

Figure 1. (a) XRD pattern of $\mathrm{BaSn}(\mathrm{OH})_{6}$ obtained by hydrothermal treatment of barium-tin hydroxide; (b) Thermogravimetry (solid line) and differential scanning calorimetry (dashed line) curves for hydrothermally-treated $\mathrm{BaSn}(\mathrm{OH})_{6}$ (upper plot) with the results of mass-spectrometry analysis of the outlet gas (lower plot). 
According to X-ray diffraction (XRD) patterns, barium stannate samples consist of well-crystallized cubic perovskite phase with a small impurity of $\mathrm{BaCO}_{3}$ (Figure 2a). The appearance of carbonate impurity in $\mathrm{BaSnO}_{3}$ was observed elsewhere, despite the hydrothermal synthesis had been performed under inert atmosphere [27]. Fourier-transformed infrared (FTIR) spectra showed the decrease of characteristic carbonate peaks at $1445 \mathrm{~cm}^{-1}$ and $855 \mathrm{~cm}^{-1}$ with the increase of annealing temperature, so that in the $\mathrm{BaSnO}_{3}-1000$ sample carbonate species were hardly detectable (Figure 2b). The major peak at $640 \mathrm{~cm}^{-1}$ is due to stretching vibrations of $\left\{\mathrm{SnO}_{6}\right\}$-octahedra [26,35]. The intensity of hydroxyl stretching band (3600-3200 $\mathrm{cm}^{-1}$ ) and Sn-OH peak at $510 \mathrm{~cm}^{-1}$ diminish with the increase of annealing temperature. As follows from Figure $2 \mathrm{a}$ and Table 1, the variation of annealing temperature in the range 275-700 ${ }^{\circ} \mathrm{C}$ had negligible effect on $\mathrm{BaSnO}_{3}$ crystallinity and microstructure parameters: the samples have close mean crystallite size $\left(d_{X R D}=18-23 \mathrm{~nm}\right)$ and specific surface area of $5-10 \mathrm{~m}^{2} / \mathrm{g}$ estimated by Brunauer-Emmett-Teller (BET) method. Imaging the samples using scanning electron microscopy (SEM) visualized polycrystalline porous structure of the surface (Figure 3). It is likely represented by agglomerates of $\mathrm{BaSnO}_{3}$ crystallites, the size of agglomerates widely distributed in the range $0.1-1 \mu \mathrm{m}$.

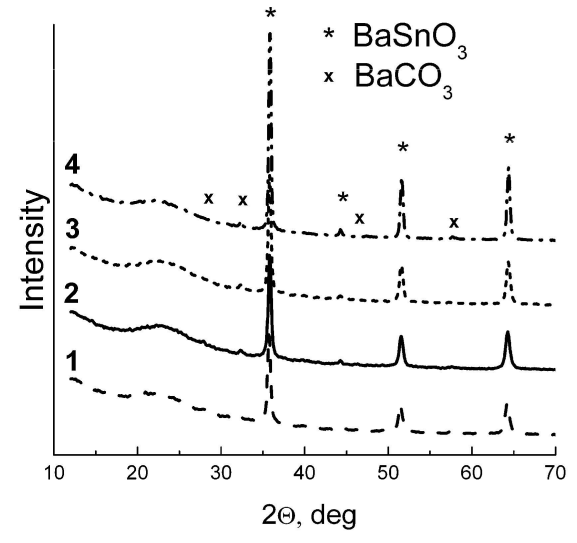

(a)

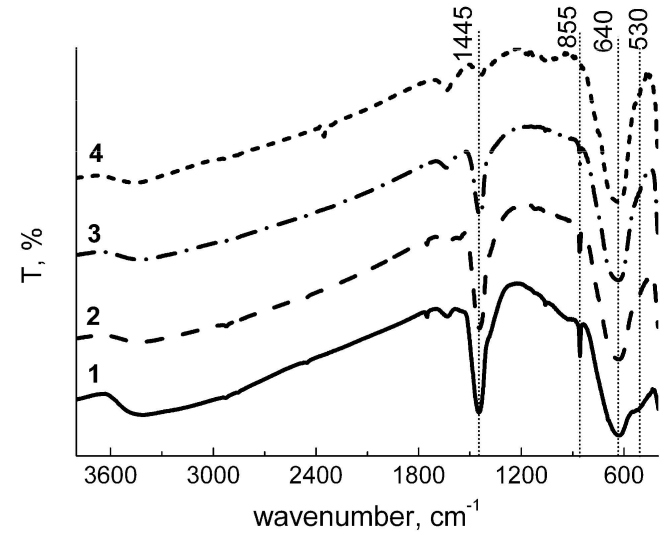

(b)

Figure 2. XRD patterns (a) and FTIR spectra (b) of $\mathrm{BaSnO}_{3}$ samples annealed at different temperatures: (1) $-275{ }^{\circ} \mathrm{C},(2)-500{ }^{\circ} \mathrm{C},(3)-700{ }^{\circ} \mathrm{C}$, and $(4)-1000{ }^{\circ} \mathrm{C}$.

Annealing barium stannate at $1000{ }^{\circ} \mathrm{C}$ resulted in a twofold increase of its mean crystallite size and respective decrease of BET area (Table 1). Noteworthy, the improved crystallinity of $\mathrm{BaSnO}_{3}-1000$ is coincident with the cleavage of carbonate impurity (Figure 2b). On the other hand, tin dioxide samples were phase-pure (XRD patterns in Supplementary data). Tin dioxide was prepared by the calcination of as-deposited and dried at $50{ }^{\circ} \mathrm{C}$ xerogel $\mathrm{SnO}_{2} \cdot \mathrm{nH}_{2} \mathrm{O}$, so that its crystallization occurred on the annealing stage. That is why its particle size and surface area were strongly dependent on the annealing temperature value. On the other hand, as-deposited barium-tin hydroxide was hydrothermally treated at $200{ }^{\circ} \mathrm{C}$ (pressure was 16-24 bar), that was necessary for $\mathrm{BaSn}(\mathrm{OH})_{6}$ phase formation and its further transformation in $\mathrm{BaSnO}_{3}$ phase during calcination. It is likely that the well-crystallized character of $\mathrm{BaSnO}_{3}$ was determined on the stage of hydrothermal treatment, so that variation of annealing temperature influenced slightly its particle size and surface area. An important factor here seems to be the presence of $\mathrm{BaCO}_{3}$ impurity which could be segregated on $\mathrm{BaSnO}_{3}$ particles and protect them from thermally induced aggregation. Alternately, the carbonate impurity because of more ionic 
character and different structure could inhibit ionic diffusion in $\mathrm{BaSnO}_{3}$ structure, thus preventing its crystallites growth. This could also explain the coincidence of carbonate disappearance and sharp increase of $\mathrm{BaSnO}_{3}$ crystallinity in the material annealed at $1000{ }^{\circ} \mathrm{C}$ and their microstructure parameters were strongly dependent on annealing temperature in the whole range (Table 1). Such a contrast in the trends of $\mathrm{BaSnO}_{3}$ and $\mathrm{SnO}_{2}$ microstructural parameters with annealing temperature could be attributed to different synthetic procedures.

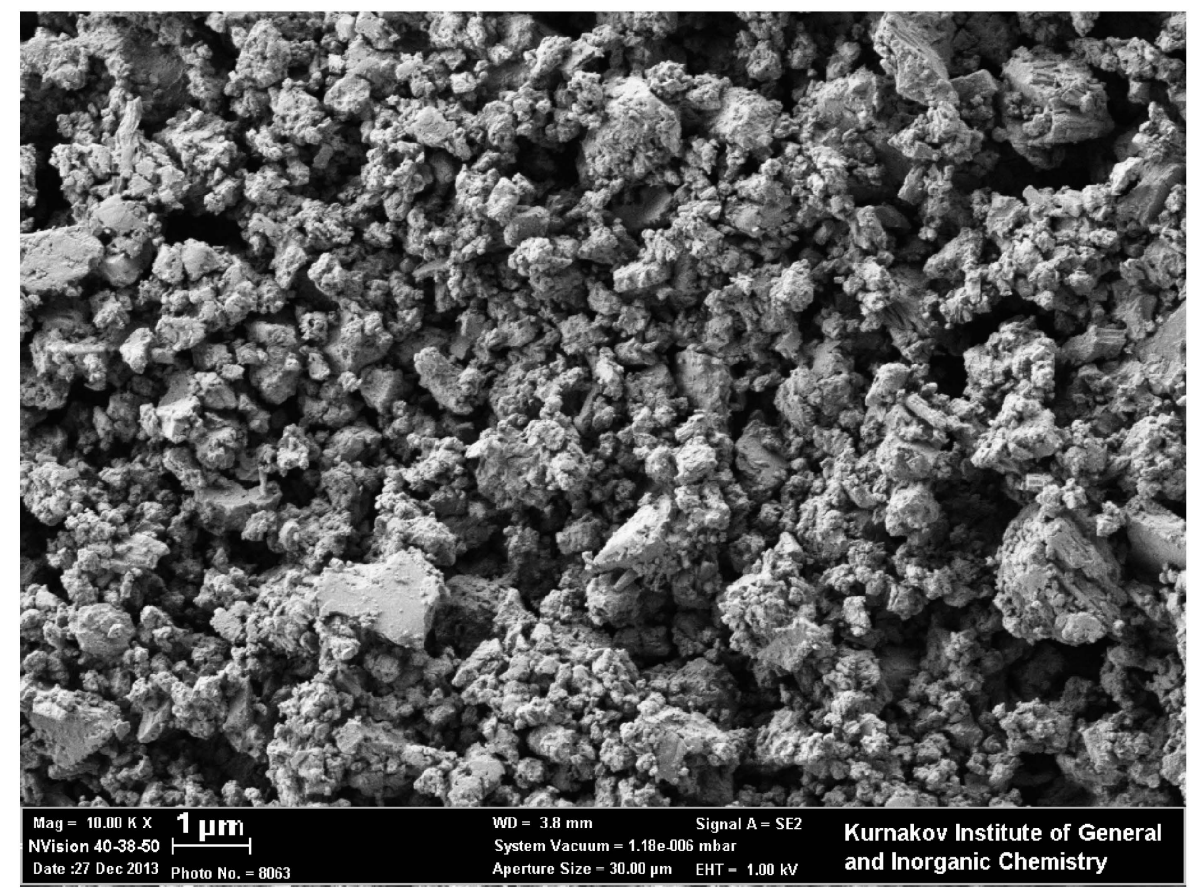

Figure 3. SEM image of $\mathrm{BaSnO}_{3}$ sample annealed at $275^{\circ} \mathrm{C}$.

Table 1. Samples designation, phase composition and microstructure parameters.

\begin{tabular}{ccccc}
\hline Sample & Annealing T, ${ }^{\circ} \mathbf{C}$ & Crystalline phase $^{\text {a }}$ & $\boldsymbol{d}_{\boldsymbol{X} \boldsymbol{R} \boldsymbol{D}}{ }^{\mathbf{b}}, \mathbf{n m}$ & BET area, $\mathbf{~}^{\mathbf{2}} \mathbf{\mathbf { g }}$ \\
\hline $\mathrm{BaSnO}_{3}-275$ & 275 & & $17-19$ & $5-7$ \\
$\mathrm{BaSnO}_{3}-500$ & 500 & $\left.\mathrm{BaSnO}_{3}\left(\text { impurity }_{\mathrm{BaCO}}\right)^{2}\right)$ & $20-22$ & $7-8$ \\
$\mathrm{BaSnO}_{3}-700$ & 700 & & $19-23$ & $6-8$ \\
\hline $\mathrm{BaSnO}_{3}-1000$ & 1000 & $\mathrm{BaSnO}_{3}$ & $40-43$ & $<2$ \\
\hline $\mathrm{SnO}_{2}-300$ & 300 & & $3-6$ & $95-100$ \\
$\mathrm{SnO}_{2}-500$ & 500 & $\mathrm{SnO}_{2}$ & $10-12$ & $20-25$ \\
$\mathrm{SnO}_{2}-700$ & 700 & & $16-20$ & $7-10$ \\
$\mathrm{SnO}_{2}-1000$ & 700 & & $26-33$ & $<5$ \\
\hline
\end{tabular}

Notes: ${ }^{\mathrm{a}}$ from XRD analysis, ${ }^{\mathrm{b}}$ from strongest XRD peaks broadening of the main phase.

\subsection{Electronic Conductance of $\mathrm{BaSnO}_{3}$ in Relation to Temperature and Oxygen Concentration}

Figure 3a shows the plot of DC-conductance $(\sigma)$ vs. reciprocal temperature for $\mathrm{BaSnO}_{3}$-based sensors measured under the atmosphere of purified air. Two regions of conductance with different activation 
energy values could be outlined from the linear $\lg \sigma-1 / \mathrm{T}$ dependences (Figure $4 \mathrm{a}$ ): the lower-temperature one at $150-300{ }^{\circ} \mathrm{C}$ and the higher-temperature one at 350-450 ${ }^{\circ} \mathrm{C}$. Such an effect at close threshold temperature but with different activation energy values was observed in other studies by DC-conduction as well as impedance measurements [16,22]. The lower-temperature activation energy has low value of $E_{A, l}=0.14-0.15 \mathrm{eV}$ and is independent on annealing temperature of the samples (Figure $4 \mathrm{~b}$ ). According to literature, it corresponds to the conduction via electron hoping by tin cations [16]. The higher-temperature activation energy $\left(E_{A, h}\right)$ tends to decrease in the range $\sim 0.5-0.3 \mathrm{eV}$ with the increase of annealing temperature of $\mathrm{BaSnO}_{3}$ from $275{ }^{\circ} \mathrm{C}$ to $1000{ }^{\circ} \mathrm{C}$ (Figure $4 \mathrm{~b}$ ). Its average value is close to the reported ionization level of double-charged oxygen $\left(\mathrm{V}_{\mathrm{O}}{ }^{\bullet}\right)$ vacancies $(0.37 \mathrm{eV}$ below Fermi level) in barium stannate [19]. The decrease of $E_{A, h}$ values with the increase of annealing temperature might result from the improved crystallinity that inhibits the formation of deep defect-state levels.

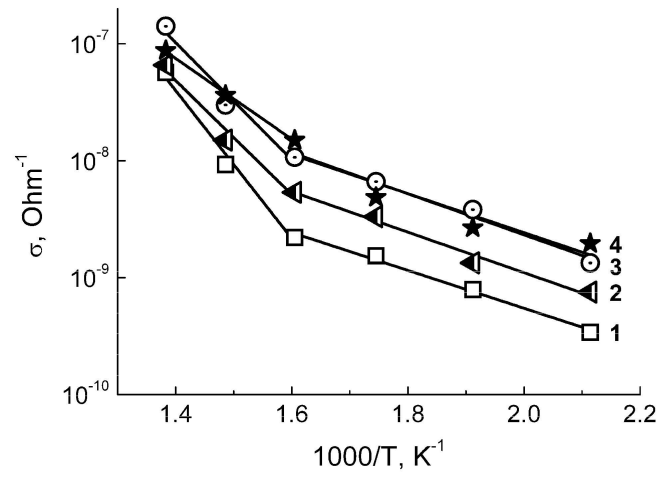

(a)

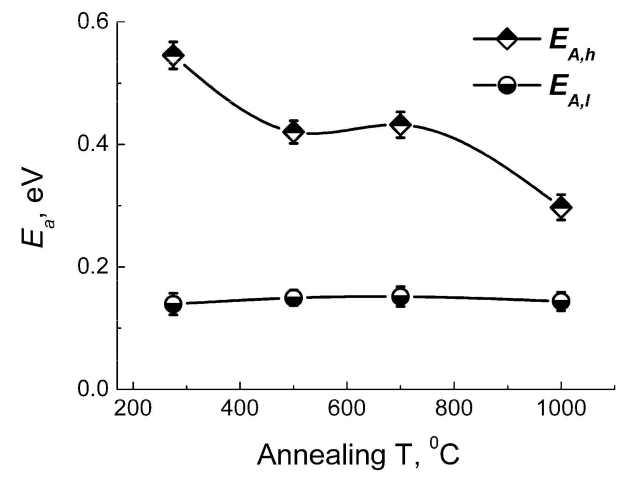

(b)

Figure 4. (a) Temperature dependence of DC-conductance $(\sigma)$ of $\mathrm{BaSnO}_{3}$ samples annealed at different temperatures: (1) $-275{ }^{\circ} \mathrm{C}$, (2) $-500{ }^{\circ} \mathrm{C}$, (3) $-700{ }^{\circ} \mathrm{C}$, and (4) $-1000{ }^{\circ} \mathrm{C}$. (b) Activation energy for conductance in relation with annealing temperature of $\mathrm{BaSnO}_{3}$. $E_{A, h}$ is activation energy at higher-temperature $\left(350-450{ }^{\circ} \mathrm{C}\right)$ and $E_{A, l}$ is activation at lower-temperature $\left(150-300^{\circ} \mathrm{C}\right)$ intervals.

By the resistance measurements at variable oxygen concentration, it was verified that at temperature $150-450{ }^{\circ} \mathrm{C}$ barium stannate exhibited $n$-type sensor response. It was evidenced by resistance increase on raising the concentration of $\mathrm{O}_{2}$ (oxidative gas) in Ar:air mixture (Figure 5a). At lower temperatures, the samples resistance exceeded the limit of measurements of the electrometer and could not be registered. From the conductance dependence on $\mathrm{O}_{2}$ partial pressure the predominant type of ionosorbed oxygen was estimated. To perform it, the data were treated using the ionosorption model developed in [36,37]. According to this, the ionosorption can be considered as the gas molecule interaction with charge carriers at the semiconductor surface:

$$
\frac{\beta}{2} O_{2, g a s}+\alpha e^{-}=O_{\beta, \text { surf }}^{\alpha-}
$$

In a stationary state when the conductance is stabilized, its value depends on the concentration of electrons able to reach the semiconductor surface $\left(n_{s}\right)$, which is dependent on both $\mathrm{O}_{2}$ gas partial pressure $p\left(\mathrm{O}_{2}\right)$ and the type of ionosorbed species ( $\alpha, \beta$ coefficients) [36]:

$$
n_{s}^{\alpha}=k_{d e s} / k_{a d s} \cdot \Theta \cdot p\left(O_{2}\right)^{-\beta / 2}
$$


where $k_{a d s}$ and $k_{d e s}$ are the rate constants of oxygen ionosorption and desorption, respectively, and $\Theta$ is the surface coverage by ionosorbed species. Applying complicated expressions for surface coverage to two model approximations, the conductance should be linearly dependent on oxygen partial pressure in logarithmic coordinates [37]

(i) for small crystallites: $\lg \sigma-\lg \left(1-\sigma / \sigma_{0}=\right.$ const $-m \cdot \lg p\left(O_{2}\right)$

(ii) for large crystallites: $\lg \sigma-\frac{1}{2} \lg \left\{\ln \left(\sigma / \sigma_{0}\right\}=\right.$ const $-m \cdot \lg p\left(O_{2}\right)$

where $\sigma$ is conductance in presence of oxygen and $\sigma_{0}$ is conductance in Ar in absence of oxygen. The approximation (i) is applied to fully depleted semiconductor particles with radius less than Debye length, while the case (ii) refers to large enough particles with size larger than Debye length and, hence, with the separation between depleted surface and not depleted bulk regions. Here it is assumed that the effect of ionosorption on electron mobility is minor in comparison with that on electron concentration [37]. Parameter $m=\beta / 2 \alpha$ is relevant to the type of ionosorbed species. For example, on the surface of tin dioxide the ionosorption route is known to be dependent on temperature: $(a)$ at $100-170{ }^{\circ} \mathrm{C}$ it yields mainly molecular $\mathrm{O}_{2}{ }^{-}$species, $(b)$ at $200-350{ }^{\circ} \mathrm{C}$-atomic $\mathrm{O}^{-}$and $(c)$ at higher temperatures-fully ionized $\mathrm{O}^{2-}$ ionosorbates [36].

The logarithmic plots of barium stannate conductance $v s$. oxygen partial pressure could be adequately fitted only using Equation (4), i.e. in the approximation to large grains (Figure 5b). This seems reasonable regarding $\mathrm{BaSnO}_{3}$ crystallite sizes in Table 1, yet no data were found in literature for the Debye length of this material. In Figure $5 \mathrm{c}$, the calculated slope values $(\mathrm{m})$ are summarized with the attribution to the type of ionosorbed oxygen species. As can be seen, within the fitting errors the ionosorption mode was similar for all $\mathrm{BaSnO}_{3}$ samples and independent on annealing temperature. It was, however, dependent on the temperature value at which the interaction with gas phase was investigated. The decrease of slope value from $m=0.7-0.8$ (at $150-200{ }^{\circ} \mathrm{C}$ ) to $m \approx 0.5\left(\right.$ at $300-400{ }^{\circ} \mathrm{C}$ ) could be interpreted as the transformation of ionosorbed oxygen from mixed $\mathrm{O}_{2}{ }^{-} / \mathrm{O}^{-}$to predominantly atomic $\mathrm{O}^{-}$species following the increase of temperature (Figure $5 \mathrm{c}$ ). This trend partially coincides with that considered above for tin dioxide. At $450{ }^{\circ} \mathrm{C}$, the slope shifted to $m \sim 0.4$, probably due to appearance of atomic $\mathrm{O}^{2-}$ ionosorbates on the surface at high temperature.

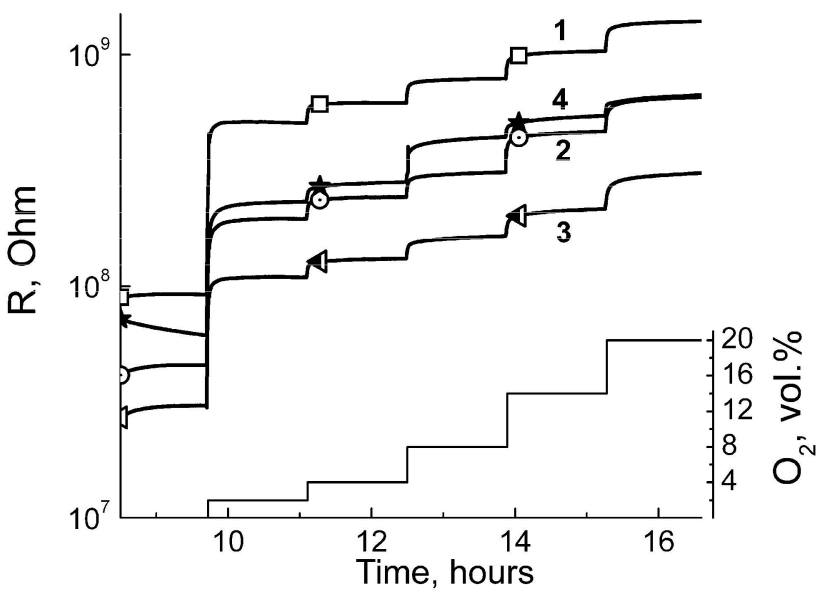

(a)

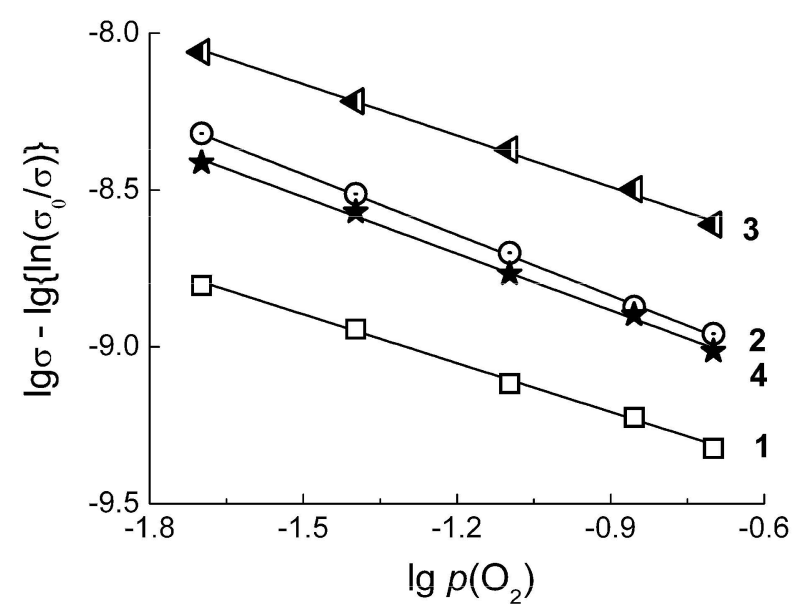

(b)

Figure 5. Cont. 


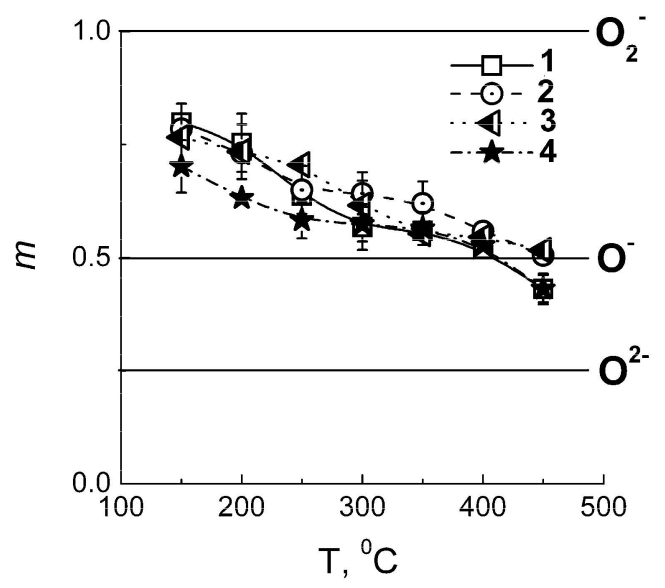

(c)

Figure 5. Resistance response to increasing $\mathrm{O}_{2}$ concentration measured at $300{ }^{\circ} \mathrm{C}(\mathbf{a})$; logarithmic conductance vs. oxygen partial pressure plot in coordinates of Equation (4) (b); and coefficient $m$ (Equation (4)) attributed to the type of ionosorbed oxygen species as a function of operating temperature (c) for $\mathrm{BaSnO}_{3}$ samples annealed at different temperatures: (1) $-275{ }^{\circ} \mathrm{C},(2)-500{ }^{\circ} \mathrm{C},(3)-700{ }^{\circ} \mathrm{C}$, and (4) $-1000{ }^{\circ} \mathrm{C}$.

\subsection{Gas Sensitivity of $\mathrm{BaSnO}_{3}$ in Comparison with $\mathrm{SnO}_{2}$}

Figure 6a shows the dynamic response for $\mathrm{BaSnO}_{3}$-based sensors and $\mathrm{SnO}_{2}-300$ reference sensor to ppm-range concentrations of various target gases measured at $300{ }^{\circ} \mathrm{C}$. (The data for $\mathrm{BaSnO}_{3}-700$ are not shown, since its resistance intersected in some cases with that of $\mathrm{SnO}_{2}-300$, which would sophisticate the representation. However, its sensing behavior was quite similar to that of $\mathrm{BaSnO}_{3}-500$. The sample $\mathrm{BaSnO}_{3}-1000$ was almost insensitive to target gases.) Both materials demonstrated $n$-type response, i.e., resistance decreases in presence of reductive target gases. Taking into account that $\mathrm{BaSnO}_{3}$ and $\mathrm{SnO}_{2}$ behave as $n$-type semiconductors because of anion vacancies $\mathrm{V}_{\mathrm{O}} \bullet^{\bullet}$, similar sensing mechanism could be anticipated for the interaction with reductive gases as it had been done elsewhere [7,38]. In principle, this process includes oxygen ionosorption during exposure in air and subsequent partial reduction of the ionosorbed species when the surface gets in contact with target gas molecules. Yet, barium stannate did not display any resistance growth on exposure to $\mathrm{NO}_{2}$ that would have been expected for an $n$-type sensing material (Figure 6a). The contrast with $\mathrm{SnO}_{2}$ may be due to smaller charge carrier concentration in $\mathrm{BaSnO}_{3}$ and/or lower energy of the donor-state level. Actually, the position of $\mathrm{V}_{\mathrm{O}} \bullet$ defect level at $0.114-0.140 \mathrm{eV}$ below Fermi level was reported for bulk tin dioxide [39], which is less than that in barium stannate $(0.37 \mathrm{eV}[19])$. Taking into account that its work function $(>5 \mathrm{eV}[40,41])$ is also higher in comparison with $\mathrm{SnO}_{2}\left(4.8 \mathrm{eV}\right.$ [42]), the deeper position of $\mathrm{V}_{\mathrm{O}} \bullet$ donor level could prevent the ionosorption of oxidizing $\mathrm{NO}_{2}$ molecules on barium stannate. Figure $6 \mathrm{~b}$ compares the sensor signal values of $\mathrm{BaSnO}_{3}-500$ and $\mathrm{SnO}_{2}-300$ to a fixed concentration of the target gases tested at $300{ }^{\circ} \mathrm{C}$. In general, the gas sensitivity of barium stannate was lower than that of tin dioxide. The sensor signal values of $\mathrm{BaSnO}_{3}$ to $\mathrm{CO}, \mathrm{NO}, \mathrm{H}_{2}$ and $\mathrm{NO}_{2}$ are well below $S=5$, which is in agreement with previous works [7-10,31,38]. The higher sensitivity of tin dioxide observed in most cases must be contributed by its much larger dispersity in comparison with $\mathrm{BaSnO}_{3}$ (Table 1). A comparable sensitivity was noted in the detection of alcohols (Figure 6b). The response to NO having close values at $300{ }^{\circ} \mathrm{C}$ was 
distinct at lower temperature: the sensitivity of $\mathrm{SnO}_{2}$ increased strongly at lower temperature $100-200{ }^{\circ} \mathrm{C}$ (Supplementary data). It was only to $\mathrm{SO}_{2}$ that barium stannate demonstrated evidently higher sensitivity than tin dioxide (Figure 6b).

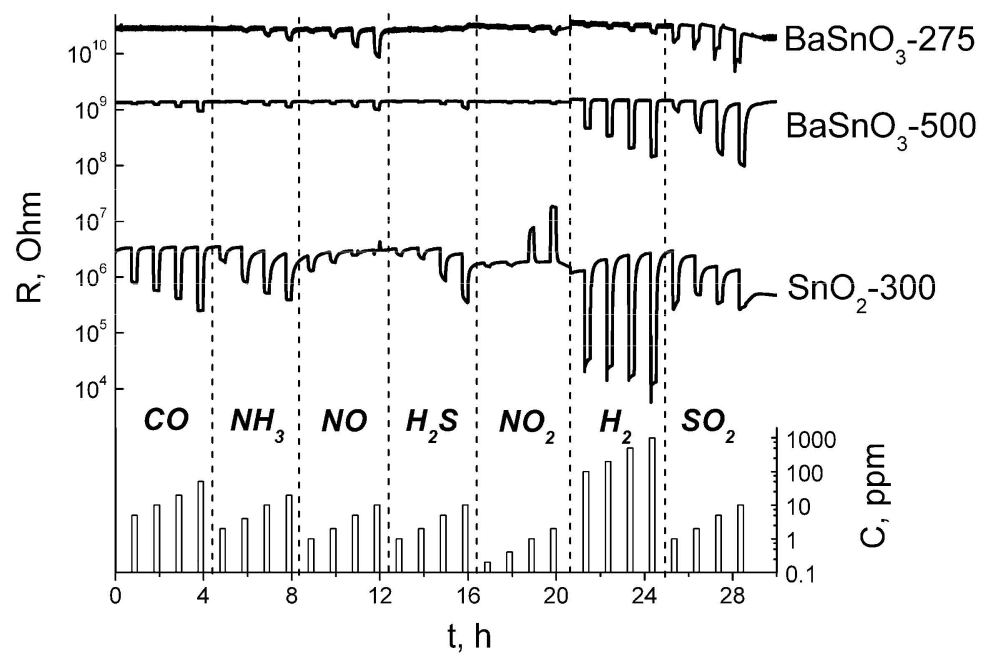

(a)

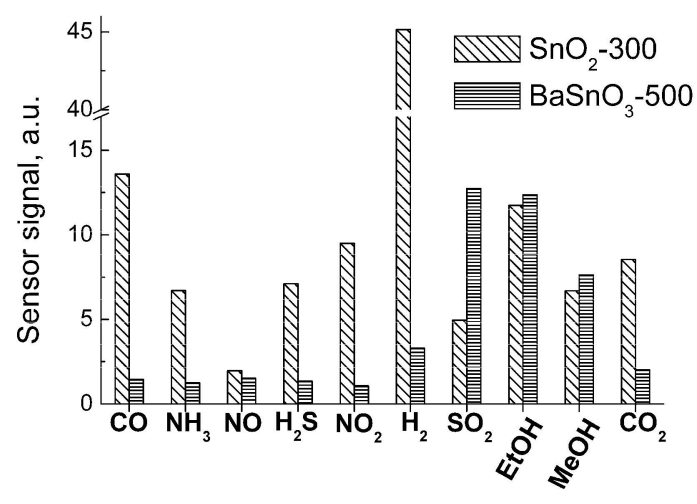

(b)

Figure 6. (a) Dynamic resistance plot of $\mathrm{BaSnO}_{3}-275, \mathrm{BaSnO}_{3}-500$ and $\mathrm{SnO}_{2}-300$ sensors to the increasing concentrations of various target gases in air measured at $300{ }^{\circ} \mathrm{C}$. (b) Sensor signals of $\mathrm{BaSnO}_{3}-500$ and $\mathrm{SnO}_{2}-300$ to target gases in air: $\mathrm{CO}$ (50 ppm), $\mathrm{NH}_{3}$ (20 ppm), $\mathrm{NO}(10 \mathrm{ppm}), \mathrm{H}_{2} \mathrm{~S}$ (2 ppm), $\mathrm{NO}_{2}$ (2 ppm), $\mathrm{H}_{2}$ (100 ppm), $\mathrm{SO}_{2}$ (10 ppm), EtOH (20 ppm), $\mathrm{MeOH}(20 \mathrm{ppm})$ and $\mathrm{CO}_{2}(1 \%) ; \mathrm{T}=300{ }^{\circ} \mathrm{C}$.

Regarding the selectivity parameter, it is appropriate to compare the sensor signals to close concentrations of target gases. From Figure $6 \mathrm{~b}$ it can be concluded that unlike $\mathrm{SnO}_{2}$, the sensitivity of barium stannate is much more dependent on the chemical nature of the target gas molecule, rather than on its concentration. Among the tested gases $\mathrm{BaSnO}_{3}$ was more sensitive to $\mathrm{SO}_{2}$ and alcohols (Figure 6b). In contrast to it, tin dioxide displayed highest signals to hydrogen since it had the highest concentration (100 ppm), then to $\mathrm{CO}(50 \mathrm{ppm})$ and lower signals to other gases with lower concentrations. The exceptions from such a correlation are the tests to $\mathrm{H}_{2} \mathrm{~S}$, which is highly adsorptive and reactive gas, $\mathrm{NO}_{2}$ (since it is an oxidative gas) and $\mathrm{CO}_{2}$ (the gas with neither reductive, nor oxidative properties). The increased sensitivity of barium stannate to EtOH in comparison to $\mathrm{CO}, \mathrm{H}_{2}, \mathrm{LPG}$ and benzene was reported in [31], which is consistent with the present results. The novel finding in this work is that the sensitivity of $\mathrm{BaSnO}_{3}$ to $\mathrm{SO}_{2}(10 \mathrm{ppm})$ exceeds its sensitivity to EtOH (20 ppm), despite the latter was tested in a higher concentration. Thus, it can be outlined that barium stannate possessed selectivity to $\mathrm{SO}_{2}$ in comparison to other target gases tested, however to confirm it the experiments on the detection of mixtures of target gases would be needed. It should be noted that there is a potential to improve selectivity of barium stannate-based sensors via it surface modification by catalytic (noble metal) clusters or acid/base (transition metal oxides) additives, doping of $\mathrm{BaSnO}_{3}$ via cation substitution in $\mathrm{Ba}$ or Sn sites that would modify surface reactivity, or by depositing filtering membranes (alumina, silica, etc.). For example, it was shown that modification by Pt increases the selectivity to LPG [9], while using $\mathrm{Al}_{2} \mathrm{O}_{3}$ additive the selectivity of barium stannate to benzene was improved [38]. 
In Figure 7a, the temperature plots of sensor signals to $\mathrm{SO}_{2}$ are summarized for all materials studied. Barium stannate samples annealed at $275-700{ }^{\circ} \mathrm{C}$ displayed close responses with the maximum at $300-350{ }^{\circ} \mathrm{C}$. Some improvement of sensitivity was noted with the increase of $\mathrm{BaSnO}_{3}$ annealing temperature to $700{ }^{\circ} \mathrm{C}$. The lack of sensitivity of $\mathrm{BaSnO}_{3}-1000$ could be due to its too low surface area. It could be noted that carbonate impurity that inhibited $\mathrm{BaSnO}_{3}$ particle size growth likely played a favorable role for the gas sensitivity of samples annealed at $275-700{ }^{\circ} \mathrm{C}$. In this context, it is important that the impurity is inactive it the process of interaction with the target gases, as is discussed below. The most interesting observation was that the responses of $\mathrm{BaSnO}_{3}$ annealed at $275-700{ }^{\circ} \mathrm{C}$ exceeded in several times those of $\mathrm{SnO}_{2}$ samples, despite the latter were favored by up to one order of magnitude larger BET surface area and smaller particle size (Table 1). The sensor signal of $\mathrm{BaSnO}_{3}$ follows the exponential dependence on $\mathrm{SO}_{2}$ concentration (Figure 7b).

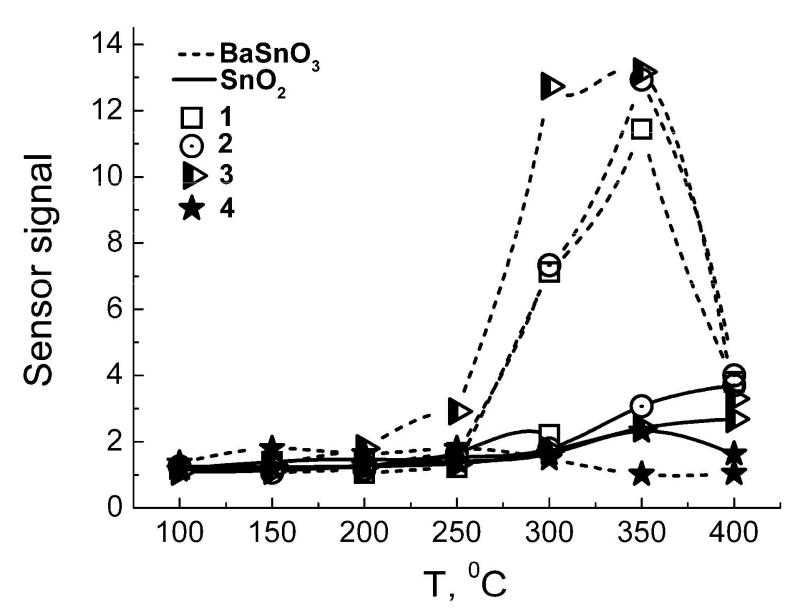

(a)

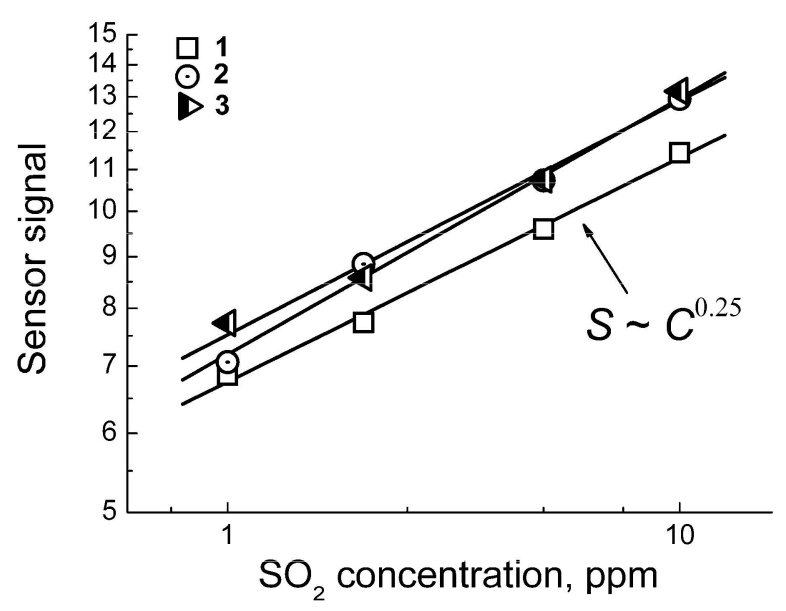

(b)

Figure 7. (a) Temperature dependence of sensor signals to $\mathrm{SO}_{2}(10 \mathrm{ppm})$ for $\mathrm{BaSnO}_{3}$ and $\mathrm{SnO}_{2}$ samples. (b) Logarithmic plot of sensor signals measured at $350{ }^{\circ} \mathrm{C} v s$. $\mathrm{SO}_{2}$ concentration for $\mathrm{BaSnO}_{3}$ samples annealed at different temperatures: (1) $-275^{\circ} \mathrm{C}$, (2) $-500{ }^{\circ} \mathrm{C},(3)-700{ }^{\circ} \mathrm{C}$, and (4) $-1000{ }^{\circ} \mathrm{C}$.

To conclude, the sensitivity of barium stannate to most target gases tested is in general lower than that of tin dioxide. This is most likely because the latter possessed much larger surface area available to interact with the gas phase. Taking into account the simpler aqueous deposition route to obtain $\mathrm{SnO}_{2}$ with BET surface area of the order $100 \mathrm{~m}^{2} / \mathrm{g}$ than the hydrothermally-assisted synthesis of barium stannate giving materials with BET surface area up to $10 \mathrm{~m}^{2} / \mathrm{g}, \mathrm{BaSnO}_{3}$-based materials have limited perspectives to be applied in gas sensing field and tin dioxide would remain being the most utilized sensing material in the detection of common atmospheric pollutants $\left(\mathrm{CO}, \mathrm{H}_{2} \mathrm{~S}, \mathrm{NH}_{3}\right.$, hydrocarbons). However, in the detection of $\mathrm{SO}_{2}$ traces in air, $\mathrm{BaSnO}_{3}$ turns out to be significantly more sensitive and selective than $\mathrm{SnO}_{2}$. This advantage can possibly be enhanced by increasing the dispersity of $\mathrm{BaSnO}_{3}$ and modifying its surface by catalytic additives of noble metals. Noteworthy, among the materials studied for $\mathrm{SO}_{2}$ detection, tin dioxide and, to a lesser extent tungsten oxide, were previously regarded as the most efficient ones, their sensitivity increasing due to surface modification by Ag, Pd and Pt additives [43]. 


\subsection{DRIFT Study of the Materials Interaction with $\mathrm{SO}_{2}$}

The reason for increased $\mathrm{SO}_{2}$ sensitivity of barium stannate was found from in situ study of the materials interaction with the target gas by means of diffuse reflectance Fourier-transform infrared spectroscopy (DRIFT). The interaction was investigated on the example of $\mathrm{BaSnO}_{3}-700$ and $\mathrm{SnO}_{2}-300$ samples as the most sensitive ones, at room temperature (adsorption regime) and at $300{ }^{\circ} \mathrm{C}$ (reaction regime). From the spectra of samples exposed to $40 \mathrm{ppm} \mathrm{SO}_{2}$ at room temperature (Figure 8a), it could be inferred that the adsorption proceeds in a not dissimilar manner on both materials. In presence of target gas, the peak arises at $1075 \mathrm{~cm}^{-1}$, which is more pronounced for $\mathrm{BaSnO}_{3}$. It can be ascribed to chemisorbed $\mathrm{SO}_{2}$ [44] as well as to $v_{3}$ asymmetric stretching vibrations of S-bound sulfite species [45]. The peak of O-bound sulfite $\left(945 \mathrm{~cm}^{-1}\right.$ [45]) was also prominent on the spectrum of $\mathrm{SnO}_{2}$ (Figure 8a). Thus, molecular chemisorption (e.g., on cation sites) along with sulfite species formation due to $\mathrm{SO}_{2}$ bonding with oxide anions took place on the surface of $\mathrm{BaSnO}_{3}$ and $\mathrm{SnO}_{2}$ at room temperature. The depletion in $\mathrm{OH}$-stretching vibration region $\left(3600-3200 \mathrm{~cm}^{-1}\right)$ could result from surface hydroxyls elimination due to competitive $\mathrm{SO}_{2}$ chemisorption.

The gas-solid interaction routes, however, were strongly distinct at raised temperature. On the surface of $\mathrm{SnO}_{2}$, molecular $\mathrm{SO}_{2}$ adsorption was the predominant interaction route at $300{ }^{\circ} \mathrm{C}$, as deduced from the evolvement of the peaks at $1345 \mathrm{~cm}^{-1}$ and $1145 \mathrm{~cm}^{-1}$ (Figure $8 \mathrm{~b}$ ). This doublet is characteristic of asymmetric $\left(v_{3}\right)$ and symmetric $\left(v_{1}\right)$ stretching bands, respectively, of adsorbed $\mathrm{SO}_{2}$ [46]. The weak adsorption character is indicated by a little shift of the peaks centers to lower wavenumbers in comparison with gas-phase molecule $\left(v_{3}=1360 \mathrm{~cm}^{-1}, v_{1}=1151 \mathrm{~cm}^{-1}\right.$ [46]). The alteration of $\mathrm{SO}_{2}$ adsorption mode on tin dioxide surface can be explained by weakening the molecule-to-surface binding at raised temperature that prevents strong chemisorption, which was observed at room temperature. On the other hand, desorption of hydroxyl species was as well intensified at raised temperature, as follows from the increased depletion of OH-stretching band at 3600-3400 $\mathrm{cm}^{-1}$ (Figure 8b). This could provide more adsorption sites for $\mathrm{SO}_{2}$ and account for the increased target gas adsorption in comparison with room-temperature situation, as follows from the comparison of S-O bands intensities at $1350-900 \mathrm{~cm}^{-1}$ in Figure 8a,b.

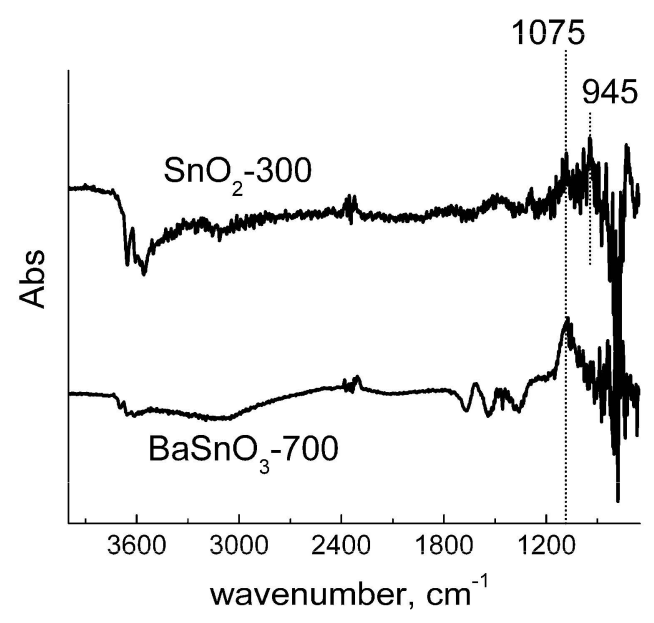

(a)

Figure 8. Cont. 


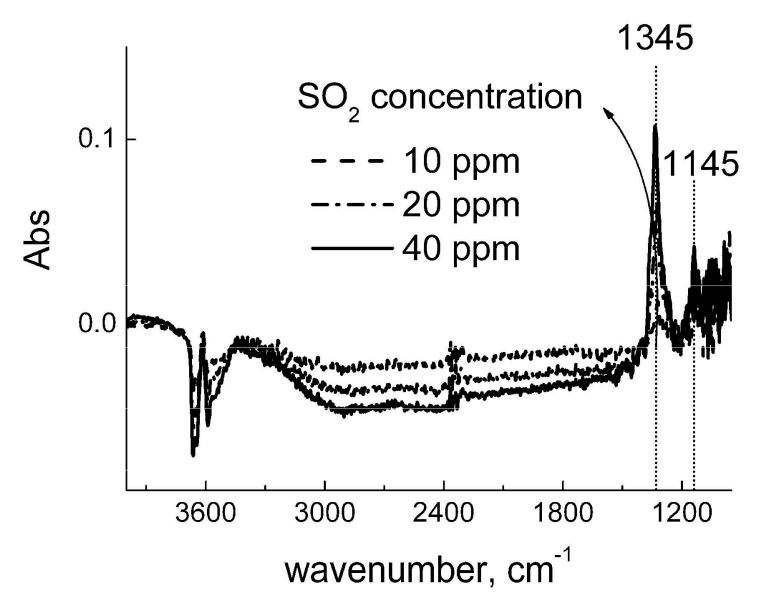

(b)

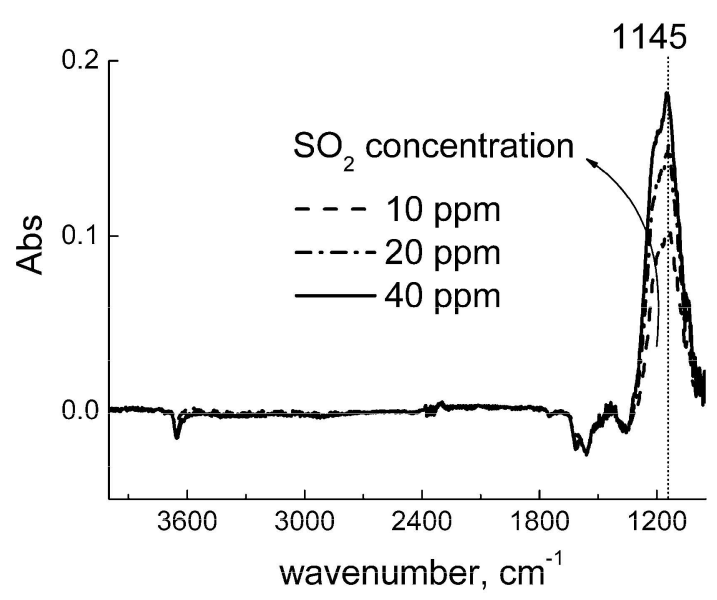

(c)

Figure 8. DRIFT spectra of $\mathrm{SnO}_{2}-300$ and $\mathrm{BaSnO}_{3}-700$ samples exposed to $\mathrm{SO}_{2}(40 \mathrm{ppm})$ at room temperature (a) DRIFT spectra of $\mathrm{SnO}_{2}-300$ sample (b) and $\mathrm{BaSnO}_{3}-700$ sample (c) exposed to increasing concentration of $\mathrm{SO}_{2}(10-20-40 \mathrm{ppm})$ at $300{ }^{\circ} \mathrm{C}$.

The main feature on the DRIFT spectra of barium stannate interacting with $\mathrm{SO}_{2}$ at $300{ }^{\circ} \mathrm{C}$ was the evolution of a strong band centered at $1145 \mathrm{~cm}^{-1}$ with a shoulder at $\sim 1200 \mathrm{~cm}^{-1}$ and a satellite at $1050 \mathrm{~cm}^{-1}$ (Figure 8c). In contrast to $\mathrm{SnO}_{2}$, the absence of a peak at $1340-1350 \mathrm{~cm}^{-1}$ ruled out that molecular adsorption took place on $\mathrm{BaSnO}_{3}$ surface. According to [45,47], this wavenumber region corresponds to asymmetric $\left(v_{3}\right)$ stretching vibration band of sulfate ions. The doublet of $1145 \mathrm{~cm}^{-1}$ and $1050 \mathrm{~cm}^{-1}$ peaks is an indicative of monodentate sulfate, while the shoulder at $1200 \mathrm{~cm}^{-1}$ suggests the presence of bidentate species as well [45]. Moreover, the set of the three peaks is typical to bulk $\mathrm{BaSO}_{4}$ [48]. Hence, $\mathrm{SO}_{2}$ oxidation is the predominant process on the surface of $\mathrm{BaSnO}_{3}$ at raised temperature. In comparison with tin dioxide, the presence of $\mathrm{Ba}^{2+}$ cations seems to play the key role in determining the interaction route. Bulk $\mathrm{BaSO}_{4}$ is known as a stable compound. The formation of its lattice fragments might be the driving force for promoting $\mathrm{SO}_{2}$ gas oxidation on the surface of $\mathrm{BaSnO}_{3}$. This is believed to be the reason for increased sensitivity of barium stannate to $\mathrm{SO}_{2}$ at raised temperature. With respect to oxygen ionosorption type (Figure 5c), the following scheme could be suggested for the improved sensing process at the temperature of maximum sensitivity $\left(300-350{ }^{\circ} \mathrm{C}\right)$ :

$$
\mathrm{Ba}_{\text {lat }}^{2+}+\mathrm{O}_{\text {lat }}^{2-}+\mathrm{O}_{\text {surf }}^{-}+\mathrm{SO}_{2, \text { gas }} \rightarrow \mathrm{BaSO}_{4, \text { surf }}+e^{-}
$$

Although a weak negative peak of hydroxyl groups was still observed at $3640 \mathrm{~cm}^{-1}$, no depletion in carbonate-vibration range $\left(\sim 1450 \mathrm{~cm}^{-1}\right)$ was detected (Figure $\left.8 \mathrm{c}\right)$. This indicates that the impurity of $\mathrm{BaCO}_{3}$ was not involved in the interaction of barium stannate with $\mathrm{SO}_{2}$. Noteworthy, no sulfate-related phases could be found after gas-solid interaction by XRD analysis.

\section{Experimental Section}

Barium stannate was synthesized by aqueous coprecipitation of freshly deposited stannic acid and barium hydroxide followed by hydrothermal treatment [26]. Stannic acid was obtained by dropwise addition of $1 \mathrm{M}$ aqueous ammonia solution to stirred $0.3 \mathrm{M}$ solution of tin (IV) chloride prepared from $\mathrm{SnCl}_{4} \cdot 5 \mathrm{H}_{2} \mathrm{O}$ (Sigma-Aldrich, St. Louis, MO, USA) until $\mathrm{pH} \sim 6$ was reached. The deposit of $\mathrm{SnO}_{2} \cdot \mathrm{nH}_{2} \mathrm{O}$ 
was washed from chloride-ions using deionized water and centrifugation. Then it was peptized in a minimum volume of $10 \mathrm{M}$ aqueous ammonia $(\mathrm{pH}>9)$ and added to $0.2 \mathrm{M} \mathrm{Ba}(\mathrm{OH})_{2}$ solution. The latter was prepared using $\mathrm{Ba}(\mathrm{OH})_{2} \cdot 8 \mathrm{H}_{2} \mathrm{O}$ (Sigma-Aldrich, St. Louis, MO, USA) and deionized water after degassing under $\mathrm{Ar}$ at $70-80{ }^{\circ} \mathrm{C}$. The mixture of precursors with the molar ratio $\mathrm{Ba}: \mathrm{Sn}=1: 1$ was stirred at $60{ }^{\circ} \mathrm{C}$ for $1 \mathrm{~h}$ under Ar flow as a protecting atmosphere. The obtained heavy white precipitate was placed in a teflone-line autoclave and hydrothermally treated at $200{ }^{\circ} \mathrm{C}$ ( $p=16-24$ bar) for $2 \mathrm{~h}$ in a microwave-heated reactor Berghof MWS-3+ (Berghof, Eningen, Germany). Next, it was washed from unreacted barium hydroxide until $\mathrm{pH} \sim 7$, decanted and dried in air at $50{ }^{\circ} \mathrm{C}$ for $24 \mathrm{~h}$. The resultant $\mathrm{BaSn}(\mathrm{OH})_{6}$ powder was divided into four parts, which were annealed in air for $24 \mathrm{~h}$ at different temperatures: $275^{\circ} \mathrm{C}, 500{ }^{\circ} \mathrm{C}, 700{ }^{\circ} \mathrm{C}, 1000^{\circ} \mathrm{C}$. The annealing temperature values were chosen on the basis of thermogravimetric analysis.

Nanocrystalline tin dioxide samples were obtained from stannic acid deposited as described above. The washed deposit of $\mathrm{SnO}_{2} \cdot \mathrm{nH}_{2} \mathrm{O}$ was dried in air at $50{ }^{\circ} \mathrm{C}$. The xerogel was separated into four parts, which were annealed at different temperatures: $300{ }^{\circ} \mathrm{C}, 500{ }^{\circ} \mathrm{C}, 700{ }^{\circ} \mathrm{C}$, and $1000{ }^{\circ} \mathrm{C}$.

$\mathrm{X}$-ray diffraction was registered using DRON-3M instrument (Burevestnik, St.-Petersburg, Russia). Crystallite size $\left(d_{\mathrm{XRD}}\right)$ was calculated from the broadening of the strongest reflexes using Scherer equation, wavelength $\lambda=1.54051 \AA\left(\mathrm{Cu} \mathrm{K} \alpha_{1}\right.$ radiation). Scanning electron microscopy (SEM) was performed using Carl Zeiss NVision 40 instrument (Carl Zeiss NTS, Oberkochen, Germany) with accelerating voltage $1-30 \mathrm{kV}$. The specific surface area of powders was estimated by nitrogen adsorption method using the Brunauer-Emmett-Teller (BET) model with the Chemisorb 2750 instrument (Micromeritics, Norcross, GA, USA). Powders (100-150 mg) were tested after pretreatment under He flow at $200{ }^{\circ} \mathrm{C}$, the probe gas was $\mathrm{N}_{2}(30$ vol \%):He. Thermogravimetric-differential scanning calorimetric analysis with mass-spectrometric detection of outlet gas (TG-DSC-MS) was performed on the NETZSCH STA 409 PC instrument (NETZSCH, Selb, Germany). Powder (20 mg) in an alumina crucible (6 mm diameter) was heated to $1000{ }^{\circ} \mathrm{C}$ with the rate of $10^{\circ} \mathrm{C} / \mathrm{min}$ under synthetic air flux (10 $\mathrm{mL} / \mathrm{min})$.

FTIR analyses were performed using Frontier (Perkin Elmer, Massachusetts, MA, USA) spectrometer in transmittance and diffuse reflectance (DRIFT) modes. The spectrometer works under ambient conditions with automatic $\mathrm{H}_{2} \mathrm{O} / \mathrm{CO}_{2}$ compensation (spectrometer self-test every $15 \mathrm{~min}$ ). In the transmittance mode, the powders $(\sim 1 \mathrm{mg})$ were ground with $50 \mathrm{mg} \mathrm{KBr}$ and pressed into pellets; the spectra were registered in $4000-400 \mathrm{~cm}^{-1}$ wavenumber region with resolution $4 \mathrm{~cm}^{-1}$ and accumulation of 4 scans. In the DRIFT mode, the gas-solid interactions were studied. Powders (30 $\mathrm{mg})$ in an alumina crucible (5 mm diameter) were placed in a heated flow camera HC900 (Pike Technologies, Fitchburg, MA, USA). The camera was mounted in the DiffusIR annex of the spectrometer. Prior to the tests, the samples were pretreated under purified air flux $(100 \mathrm{~mL} / \mathrm{min})$ for $1.5 \mathrm{~h}$ at a constant temperature corresponding to the subsequent measurement. Generator of purified air (model " $1,2-3,5$ ", Himelectronica, Moscow, Russia) was used as the carrier gas source, contaminations level according to the manufacturer guarantee not exceeding: $\mathrm{H}_{2} \mathrm{O}-10 \mathrm{ppm}, \mathrm{CO}_{2}-2 \mathrm{ppm}$, and hydrocarbons $-0.1 \mathrm{ppm}$. The pretreatment completeness was checked by the absence of spectral changes due to water desorption during 15-30 min. After this, the background spectrum was collected. During the test, relative IR absorbance spectra were registered every $5 \min$ in $4000-650 \mathrm{~cm}^{-1}$ wavenumber region with resolution 
$4 \mathrm{~cm}^{-1}$ and accumulation of 4 scans $(0.7 \mathrm{~min}$ for a spectrum collection). From the beginning of the measurements, the samples were exposed to purified air flux for $30 \mathrm{~min}$ more to verify that baseline was zero. Next, the flux $(100 \mathrm{~mL} / \mathrm{min})$ was switched to the test gas; it was purged for $1 \mathrm{~h}$ at a constant temperature in the range of $25-300{ }^{\circ} \mathrm{C}$. The test gas was $\mathrm{SO}_{2}(10 \mathrm{ppm}, 20 \mathrm{ppm}, 40 \mathrm{ppm})$ in purified air. The source of test gas was certified gas mixture of $\mathrm{SO}_{2}$ (96 $\pm 5 \mathrm{ppm}$ ): $\mathrm{N}_{2}$ (Linde-Gas, Moscow, Russia).

To perform DC-resistance measurements the sensor samples were prepared. Powders were ground with a binder (terpeniol). The obtained paste was drop-deposited onto alumina microhotplates provided with vapor-deposited rectangular-shaped Pt contacts $(0.3 \mathrm{~mm} \times 0.2 \mathrm{~mm})$ separated by $0.2 \mathrm{~mm}$ gap and with embedded Pt-heaters. The sensing layer (5-7 $\mu \mathrm{m}$ thick) covered area of $1.0 \mathrm{~mm} \times 0.5 \mathrm{~mm}$. As-prepared sensors were placed in a flow chamber of a resistance measuring device. Prior to measurements, the sensors were annealed at $300{ }^{\circ} \mathrm{C}$ for $14 \mathrm{~h}$ under purified air flux $(100 \mathrm{~mL} / \mathrm{min})$ to remove the binder and/or to clean the surface from adsorbed humidity. Resistance measurements were performed in situ during the sensors exposure to a gas flow $(100 \mathrm{~mL} / \mathrm{min})$ at a constant temperature in the range $100-450{ }^{\circ} \mathrm{C}$. Temperature dependence of resistance was measured under purified air. The resistance dependence on oxygen concentration was measured using gas mixtures of purified air with analytical grade $\operatorname{Ar}\left(0-2-4-8-14-20\right.$ vol.\% $\mathrm{O}_{2}$ ). In sensing tests, the flow was purged through the chamber in a pulsed regime: background gas-test gas-background gas, etc., the exposure time was $15 \mathrm{~min}$, recovery time $-45 \mathrm{~min}$. Purified air was used as the background gas. The test gases were: $\mathrm{CO}(5-50 \mathrm{ppm}), \mathrm{NH}_{3}(2-20 \mathrm{ppm})$,

NO (1-10 ppm), $\quad \mathrm{H}_{2} \mathrm{~S}(0.2-2 \mathrm{ppm}), \quad \mathrm{NO}_{2}(0.2-2 \mathrm{ppm}), \quad \mathrm{H}_{2}(100-1000 \mathrm{ppm}), \quad \mathrm{SO}_{2}(1-10 \mathrm{ppm})$, EtOH (20-200 ppm), MeOH (20-200 ppm) and $\mathrm{CO}_{2}(1 \%)$. The analyte sources were certified gas mixtures: $\mathrm{CO}(517 \pm 12 \mathrm{ppm}): \mathrm{N}_{2}, \mathrm{NH}_{3}(209 \pm 8 \mathrm{ppm})$ :air, $\mathrm{NO}(98 \pm 8 \mathrm{ppm}), \mathrm{H}_{2} \mathrm{~S}(51 \pm 2 \mathrm{ppm}): \mathrm{N}_{2}$, $\mathrm{NO}_{2}(21.4 \pm 0.9 \mathrm{ppm}): \mathrm{N}_{2}, \mathrm{H}_{2}(1.0 \pm 0.1 \%): \mathrm{N}_{2}, \mathrm{SO}_{2}(96 \pm 4 \mathrm{ppm}): \mathrm{N}_{2}, \mathrm{CO}_{2}(10.4 \pm 0.5 \%)$ :air; liquid $\mathrm{EtOH}$ and $\mathrm{MeOH}$ (Sigma-Aldrich, St. Louis, MO, USA). Test gases were prepared by the analytes dilution in purified air. The sensor signal $S=R_{\text {air }} / R_{\text {gas }}$ was defined as a ratio of resistance under background gas $\left(R_{\text {air }}\right)$ to that under test gas $\left(R_{\text {gas }}\right)$.

\section{Conclusions}

Cubic perovskite-type barium stannate was synthesized via aqueous coprecipitation with microwave-assisted hydrothermal treatment. Its particle size of 18-23 nm and BET surface area of $5-10 \mathrm{~m}^{2} / \mathrm{g}$ were unaffected by annealing temperature in the range $275-700{ }^{\circ} \mathrm{C}$. Raising the annealing temperature to $1000{ }^{\circ} \mathrm{C}$ resulted in twofold increase of $\mathrm{BaSnO}_{3}$ crystallite size and decrease of BET surface area along with the elimination of carbonate impurity. Nanocrystalline tin dioxide was synthesized for comparison, its particle size (from 3-6 nm to 26-33 nm) and BET surface area (from $<5$ to $95-100 \mathrm{~m}^{2} / \mathrm{g}$ ) being strongly dependent on annealing temperature in the range $300-1000{ }^{\circ} \mathrm{C}$. Barium stannate showed $n$-type semiconductor behavior with the activation energy of $0.14-0.15 \mathrm{eV}$ at $150-300{ }^{\circ} \mathrm{C}$ supposedly due to electron hopping mechanism of conductance. At higher temperature $\left(350-450{ }^{\circ} \mathrm{C}\right)$, the activation energy decreased with the increase of $\mathrm{BaSnO}_{3}$ crystallinity, its average value being comparable to the ionization energy of oxygen vacancies. Comparative tests of sensor responses of $\mathrm{BaSnO}_{3}$ and $\mathrm{SnO}_{2}$ to ppm-level traces of various target gases in air were performed. An increased $\mathrm{SO}_{2}$ sensitivity of barium stannate was observed, despite tin dioxide having one order of magnitude 
larger BET area and smaller particle size. The reason for it was revealed from in situ DRIFT study of the materials interaction with $\mathrm{SO}_{2}$. Although adsorption at room temperature proceeded similarly on $\mathrm{BaSnO}_{3}$ and $\mathrm{SnO}_{2}$, at raised temperature the interaction routes were distinct. Unlike tin dioxide on the surface of which mostly molecular adsorption occurred, on the surface of $\mathrm{BaSnO}_{3}$ the oxidation of $\mathrm{SO}_{2}$ was the predominant process. Barium-promoted formation of surface sulfate species was recognized as the factor favoring target gas molecules oxidation that is responsible for increased $\mathrm{SO}_{2}$ sensitivity of barium stannate.

\section{Acknowledgments}

The authors acknowledge Russian Science Foundation (grant 14-19-00120) for financial support.

\section{Author Contributions}

All authors made great contributions to the development of this manuscript. Artem Marikutsa, Marina Rumyantseva and Alexander Baranchikov performed the experimental works. All authors participated in the analysis of the results. Alexander Gaskov greatly contributed to the concept, discussion and revising of the manuscript.

\section{Conflicts of Interest}

The authors declare no conflict of interest.

\section{References}

1. Eranna, G.; Joshi, B.C.; Runthala, D.P.; Gupta, R.P. Oxide materials for development of integrated gas sensors-A comprehensive review. Crit. Rev. Solid State Mater. Sci. 2004, 29, 111-188. [CrossRef]

2. Morrison, S.R. The Chemical Physics of Surfaces; Plenum Press: New York, NY, USA, 1977; p. 403.

3. Rumyantseva, M.N.; Gaskov, A.M. Chemical modification of nanocrystalline metal oxides: Effect of the real structure and surface chemistry on the sensor properties. Russ. Chem. Bull. 2008, 57, 1106-1125. [CrossRef]

4. Hosono, H. Ionic amorphous oxide semiconductors: Material design, carrier transport, and device application. J. Non Cryst. Solids 2006, 352, 851-858. [CrossRef]

5. Kamiya, T.; Hosono, H. Material characteristics and applications of transparent amorphous oxide semiconductors. NPG Asia Mater. 2010, 2, 15-22. [CrossRef]

6. Hosono, H. Recent progress in transparent oxide semiconductors: Materials and device application. Thin Solid Films 2007, 515, 6000-6014. [CrossRef]

7. Lampe, U.; Gerblinger, J.; Meixner, H. Carbon-monoxide sensors based on thin films of $\mathrm{BaSnO}_{3}$. Sens. Actuators B 1995, 25, 657-660. [CrossRef]

8. Lampe, U.; Gerblinger, J.; Meixner, H. Nitrogen oxide sensors based on thin films of $\mathrm{BaSnO}_{3}$. Sens. Actuators B 1995, 26, 97-98. [CrossRef] 
9. Gopal Reddy, C.V.; Manorama, S.V.; Rao, V.J. Preparation and characterization of barium stannate: Application as a liquefied petroleum gas sensor. J. Mater. Sci. Mater. Electron. 2001, 12, 137-142. [CrossRef]

10. Cerda, J.; Arbiol, J.; Dezanneau, G.; Dıaz, R.; Morante, J.R. Perovskite-type $\mathrm{BaSnO}_{3}$ powders for high temperature gas sensor applications. Sens. Actuators B 2002, 84, 21-25. [CrossRef]

11. Yasukawa, M.; Kono, T.; Ueda, K.; Yanagi, H.; Hosono, H. High-temperature thermoelectric properties of La-doped $\mathrm{BaSnO}_{3}$ ceramics. Mater. Sci. Eng. B 2010, 173, 29-32. [CrossRef]

12. Upadhyay, S.; Parkash, O.; Kumar, D. Solubility of lanthanum, nickel and chromium in barium stannate. Mater. Lett. 2001, 49, 251-255. [CrossRef]

13. Lu, W.; Jiang, S.; Zhou, D.; Gong, S. Structural and electrical properties of $\mathrm{Ba}(\mathrm{Sn}, \mathrm{Sb}) \mathrm{O}_{3}$ electroceramics materials. Sens. Actuators B 2000, 80, 35-37. [CrossRef]

14. Larramona, G.; Gutierrez, C.; Pereira, I.; Rosa Nunes, M.; da Costa, F.M.A. Characterization of the mixed perovskite $\mathrm{BaSn}_{1-\mathrm{x}} \mathrm{Sb}_{\mathrm{x}} \mathrm{O}_{3}$ by electrolyte electroreflectance, diffuse reflectance, and X-Ray photoelectron spectroscopy. J. Chem. Soc., Faraday Trans. 1 1989, 85, 907-916. [CrossRef]

15. Cava, R.J.; Gammel, P.; Batlogg, B.; Krajewski, J.J.; Peck, W.F., Jr.; Rupp, L.W., Jr.; Felder, R.; van Dover, R.B. Nonsuperconducting $\mathrm{BaSn}_{1-\mathrm{x}} \mathrm{Sb}_{\mathrm{x}} \mathrm{O}_{3}$ : The 5s-orbital analog of $\mathrm{BaPb}_{1-\mathrm{x}} \mathrm{Bi}_{\mathrm{x}} \mathrm{O}_{3}$. Phys. Rev. B 1990, 42, 4815-4818. [CrossRef]

16. Upadhyay, S.; Parkash, O.; Kumar, D. Synthesis, structure and electrical behaviour of nickel-doped barium stannate. J. Alloys Compd. 2007, 432, 258-264. [CrossRef]

17. Doroftei, C.; Popa, P.D.; Iacomi, F. Study of the influence of nickel ions substitutes in barium stannates used as humidity resistive sensors. Sens. Actuators A 2012, 173, 24-29. [CrossRef]

18. Mizoguchi, H.; Woodward, P.M.; Park, C.H.; Keszler, D.A. Strong near-infrared luminescence in $\mathrm{BaSnO}_{3}$. J. Am. Chem. Soc. 2004, 126, 9796-9800. [CrossRef] [PubMed]

19. Scanlon, D.O. Defect engineering of $\mathrm{BaSnO}_{3}$ for high-performance transparent conducting oxide applications. Phys. Rev. B 2013, 87. [CrossRef]

20. Mizoguchi, H.; Eng, H.W.; Woodward, P.M. Probing the Electronic Structures of Ternary Perovskite and Pyrochlore Oxides Containing $\mathrm{Sn}^{4+}$ or $\mathrm{Sb}^{5+}$. Inorg. Chem. 2004, 43, 1667-1680. [CrossRef] [PubMed]

21. Moreira, E.; Henriques, J.M.; Azevedo, D.L.; Caetano, E.W.S.; Freire, V.N.; Fulco, U.L.; Albuquerque, E.L. Structural and optoelectronic properties, and infrared spectrum of cubic $\mathrm{BaSnO}_{3}$ from first principles calculations. J. Appl. Phys. 2012, 112. [CrossRef]

22. Kuferstein, R.; Yakuphanoglu, F. Semiconducting properties of Ge-doped $\mathrm{BaSnO}_{3}$ ceramic. J. Alloys Compd. 2010, 506, 678-682. [CrossRef]

23. Upadhyay, S.; Parkash, O.; Kumar, D. Preparation and characterization of barium stannate $\mathrm{BaSnO}_{3}$. J. Mater. Sci. Lett. 1997, 16, 1330-1332. [CrossRef]

24. Bajpai, P.K.; Ratre, K.; Pastor, M.; Sinha, T.P. Preparation, characterization and dielectric behaviour of some yttrium doped strontium stannates. Bull. Mater. Sci. 2003, 26, 461-464. [CrossRef]

25. Kutty, T.R.N.; Vivekanadan, R. $\mathrm{BaSnO}_{3}$ fine powders from hydrothermal preparations. Mater. Res. Bull. 1987, 22, 1457-1465. [CrossRef]

26. Lu, W.; Schmidt, H. Preparation and characterization of $\mathrm{BaSnO}_{3}$ powders by hydrothermal synthesis from tin oxide hydrate gel. J. Mater. Sci. 2007, 42, 10007-10013. [CrossRef] 
27. Guo, F.; Li, G.; Yang, N.; Wang, W.; Zhang, W. Preparation and photophysical properties of rhombic dodecahedral perovskite-type $\mathrm{BaSnO}_{3}$. Appl. Phys. A 2012, 107, 813-817. [CrossRef]

28. Udawatte, C.P.; Yoshimura, M. Preparation of well-crystallized $\mathrm{BaSnO}_{3}$ powders under hydrothermal conditions. Mater. Lett. 2001, 47, 7-10. [CrossRef]

29. Lu, W.; Schmidt, H. Lyothermal synthesis of nanocrystalline $\mathrm{BaSnO}_{3}$ powders. Ceram. Int. 2008, 34, 645-649. [CrossRef]

30. Cerda, J.; Arbiol, J.; Diaz, R.; Dezanneau, G.; Morante, J.R. Synthesis of perovskite-type $\mathrm{BaSnO}_{3}$ particles obtained by a new simple wet chemical route based on a sol-gel process. Mater. Lett. 2002, 56, 131-136. [CrossRef]

31. Tao, S.; Gao, F.; Liu, X.; Sorensen, O.T. Ethanol-sensing characteristics of barium stannate prepared by chemical precipitation. Sens. Actuators B 2000, 71, 223-227. [CrossRef]

32. Udawatte, C.P.; Kakihana, M.; Yoshimura, M. Preparation of pure perovskite-type $\mathrm{BaSnO}_{3}$ powders by the polymerized complex method at reduced temperature. Solid State Ionics 1998, 108, 23-30. [CrossRef]

33. Upadhyay, S.; Kavitha, P. Lanthanum doped barium stannate for humidity sensor. Mater. Lett. 2007, 61, 1912-1915. [CrossRef]

34. Ostrick, B.; Fleischer, M.; Lampe, U.; Meixner, H. Preparation of stoichiometric barium stannate thin films: Hall measurements and gas sensitivities. Sens. Actuators B 1997, 44, 601-606. [CrossRef]

35. Kumari, U.S.; Suresh, P.; Prasada Rao, A.V. Solid-state metathetic synthesis of phase pure $\mathrm{BaSnO}_{3}$ and $\mathrm{BaZrO}_{3}$. Int. Res. J. Pure Appl. Chem. 2013, 3, 347-356. [CrossRef]

36. Barsan, N.; Weimar, U. Conduction model of metal oxide gas sensors. J. Electroceram. 2001, 7, 143-167. [CrossRef]

37. Rumyantseva, M.N.; Makeeva, E.A.; Badalyan, S.M.; Zhukova, A.A.; Gaskov, A.M. Nanocrystalline $\mathrm{SnO}_{2}$ and $\mathrm{In}_{2} \mathrm{O}_{3}$ as materials for gas sensors: The relationship between microstructure and oxygen chemisorption. Thin Solid Films 2009, 518, 1283-1288. [CrossRef]

38. Kocemba, I.; Wrobel-Jedrzejewska, M.; Szychowska, A.; Rynkowski, J.; Glowka, M. The properties of barium stannate and aluminum oxide-based gas sensor. The role of $\mathrm{Al}_{2} \mathrm{O}_{3}$ in this system. Sens. Actuators B 2007, 121, 401-405. [CrossRef]

39. Kilic, C.; Zunger, A. Origins of coexistence of conductivity and transparency in $\mathrm{SnO}_{2}$. J. Phys. Rev. Lett. 2002, 88. [CrossRef]

40. Gopal Reddy, C.V.; Manorama, S.V.; Rao, V.J.; Lobo, A.; Kulkarni, S.K. Noble metal additive modulation of gas sensitivity of $\mathrm{BaSnO}_{3}$, explained by a work function based model. Thin Solid Films 1999, 348, 261-265. [CrossRef]

41. Manorama, S.V.; Gopal Reddy, C.V.; Rao, V.J. X-ray photoelectron spectroscopic studies of noble metal-incorporated $\mathrm{BaSnO}_{3}$ based gas sensors. Appl. Surf. Sci. 2001, 174, 93-105. [CrossRef]

42. Islam, M.N.; Hakim, M.O. Electron affinity and work function of polycrystalline $\mathrm{SnO}_{2}$ thin film. J. Mater. Sci. Lett. 1986, 5, 63-65. [CrossRef]

43. Kanan, S.M.; El-Kadri, O.M.; Abu-Yousef, I.A.; Kanan, M.C. Semiconducting metal oxide based sensors for selective gas pollutant detection. Sensors 2009, 9, 8158-8196. [CrossRef] [PubMed] 
44. Karge, H.G.; Dalla Lana, I.G. Infrared studies of $\mathrm{SO}_{2}$ adsorption on a Claus catalyst by selective poisoning of sites. J. Phys. Chem. 1984, 88, 1538-1543. [CrossRef]

45. Nakamoto, K. Infrared and Raman Spectra of Inorganic and Coordination Compounds. Part B: Applications in Coordination, Organometallic and Bioinorganic Chemistry, 6th ed.; Wiley: Hoboken, NJ, USA, 2009.

46. Marcu, I.C.; Sandulescu, I. Study of sulfur dioxide adsorption on Y zeolite. J. Serb. Chem. Soc. 2004, 69, 563-569. [CrossRef]

47. Periasamy, A.; Muruganand, S.; Palaniswamy, M. Vibrational studies of $\mathrm{Na}_{2} \mathrm{SO}_{4}, \mathrm{~K}_{2} \mathrm{SO}_{4}, \mathrm{NaHSO}_{4}$ and $\mathrm{KHSO}_{4}$ crystals. RASAYAN J. Chem. 2009, 2, 981-989.

48. Kalbus, G.E.; Lieu, V.T.; Kalbus, L.H. Infrared examination of the transformation of barium sulfate into barium carbonate. J. Chem. Educ. 2006, 83, 910-912. [CrossRef]

(C) 2015 by the authors; licensee MDPI, Basel, Switzerland. This article is an open access article distributed under the terms and conditions of the Creative Commons Attribution license (http://creativecommons.org/licenses/by/4.0/). 